\title{
Simulation and detection of flaws in pre-cured CFRP using laser displacement sensing
}

\author{
Nick Miesen $^{1,2} \cdot$ Jos Sinke $^{2} \cdot$ Roger M. Groves ${ }^{1} \cdot$ Rinze Benedictus $^{2}$
}

Received: 31 October 2014 / Accepted: 11 May 2015 / Published online: 11 June 2015

(C) The Author(s) 2015. This article is published with open access at Springerlink.com

\begin{abstract}
The novelty of the research is the detection of different types of flaws in the prepreg carbon fibre-reinforced fibres (CFRP) layup compared to in cured products. This paper presents the development of a new method for in situ detection of prepreg CFRP production flaws combining laser displacement sensors and analytical modelling. Experimental results are used to validate the results from the models. The pre-cured flaws are simulated to determine the needed specifications of the measurement system. In static and dynamic experiments, the typical production flaws are detected to demonstrate the use of laser displacement sensing as a preventative non-destructive evaluation (NDE) system. During the production of CFRP materials, flaws can be introduced due to the process of layup or curing. Once a production flaw is embedded and cured in the CFRP laminate, the damage is irreversible and it is expensive to rework or remanufacture the product. Laser displacement sensing is currently used in a wide range of applications in industrial manufacturing and is successfully assessed in this research as a preventative NDE system.
\end{abstract}

Keywords Laser displacement sensing · Preventative NDE • CFRP · Layup process

Nick Miesen

n.miesen@tudelft.nl

1 Aerospace Non-Destructive Testing Laboratory, Faculty of Aerospace Engineering, Delft University of Technology (TU Delft), Kluyverweg 1, Delft 2629HS, The Netherlands

2 Structural Integrity \& Composites Group, Faculty of Aerospace Engineering, Delft University of Technology (TU Delft), Kluyverweg 1, Delft 2629HS, The Netherlands

\section{Introduction}

Carbon fibre-reinforced fibres (CFRP) are used more and more in the aerospace industry, because of several advantages, such as lightweight construction and design flexibility $[1,2]$. In a composite manufacturing facility, the non-destructive evaluation (NDE) phase evaluates products for deviations from the design specifications after production [1,2], to ensure high-quality products. These production flaws decrease the level of manufacturing efficiency and increase the costs of CFRP production. This research paper will concentrate on the top 5 production flaws during the layup phase that were indicated by the industry in a survey conducted by the authors in 2013 and are presented in Table 1. The typical flaw size in height is provided in the table for correct reference in the models and experiments. Current quality assurance systems are not suited to detect these production flaws before curing, so a candidate preventative NDE system must be capable of measuring these deviations. The combination of the geometrical measurements, location and design specifications will provide the input to a new quality assurance system for the layup production of CFRP laminates. If an in situ monitoring system can detect these flaws during the layup, the layup can be stopped immediately to remove any enclosures or verify problems.

Optical techniques are non-contact and familiar techniques in production environment for measurements in industrial applications [3]. Laser displacement sensing (LDS) is widely used to measure the geometrical dimensions of test specimens, where a point or line laser signal is projected on the object and the reflected or scattered signal is processed [4]. LDS has a wide range of application in industry [4-8] as these sensors are used in robotics, autonomous vehicles, anti-collision and proximity sensors. The sensors are also used in industrial manufacturing to monitor the quality in automatic line 
Table 1 Typical flaws in CFRP production and expected sizes in height

\begin{tabular}{ll}
\hline Flaw type & $\begin{array}{l}\text { Typical flaw size } \\
\text { in height }(\mu \mathrm{m})\end{array}$ \\
\hline Unremoved foil or other enclosed anomalies & 50 \\
Incorrect number of layers & 160 \\
Incorrect fibre orientation & 5 \\
Fibre bridging/wrinkling & 200 \\
Incorrect overlap & 160
\end{tabular}

Flaws are listed in order of number of occurrences

production, such as a vision inspection sensor system for the automation of laser welding processes in heavy industries. In the aerospace industry, the sensors are used for precise measurements of surface defects and for contour measurements during manufacturing [9]. Previous work related to LDS in composite production has focused more on the automated control of the tape laying process. Schmitt et al. [10-13] detected production misalignments during manual layup of fibre-reinforced plastics (FRP). Schmitt et al. succeeded in contour scanning the FRP specimen and detecting out-ofplane defects. The low reflectivity and diffuse reflection of the FRP material were bottlenecks and were solved by developing a new evaluation algorithm. Other related research was performed by Faidi et al. at GE Global Research Center [14]. Faidi et al. investigated an in-line inspection system to improve the automated production of carbon composite wind turbine blade spar caps, and they successfully detected wrinkles in the range of 0.5 to $1 \mathrm{~mm}$ in height. Both Schmitt et al. and Faidi et al. tested LDS in a CFRP production environment, but did not included typical production flaws or the needed measurement accuracy. The novelty of the research is the detection of different types of flaws of the prepreg CFRP layup compared to post-cured products and if LDS is suitable for use as a preventative NDE technique to detect these typical production flaws in prepreg CFRP.

Section 2 describes the working principle of the laser displacement technique, and section 3 describes the simulated CFRP specimens. Section 4 describes the experiments and set-ups of the proposed research. The results are presented in section 5 and are discussed in section 6. Section 7 concludes the research and assesses the suitability of LDS as an in situ monitoring system for CFRP production.

\section{Laser displacement sensors}

LDS with triangulation sensors are based on calibrated detection sensors with a reference laser source, see Fig. $1[4,15]$. The basic principle is to project and receive a laser signal from an object in order to determine its distance from the sensor. The set-up of the measurement system will make sure that the
Laser displacement sensor head

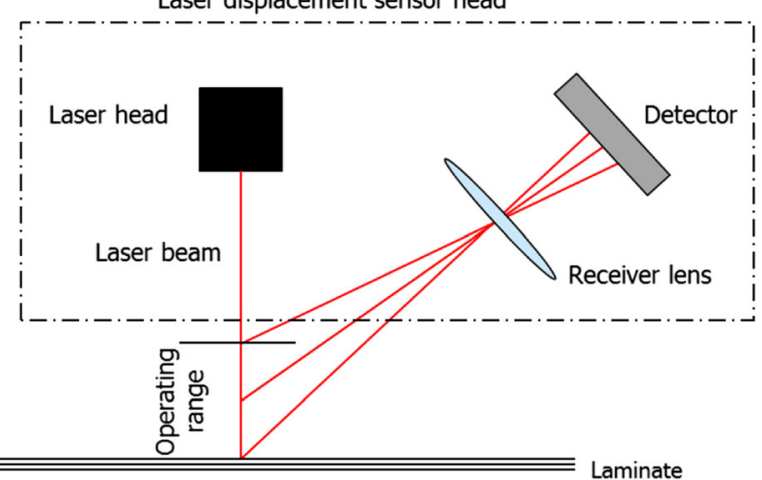

Fig. 1 A laser head projects laser light onto an object within the operating range, and scattered or reflected light is received by a detector to determine the distance from the laser head with triangulation

photodetector is in focus relative to the collecting lens, where the size of the photodetector determines the operating range. The operating range is defined as the minimum and maximum distance to the object from the laser source, as shown in Fig. 1. Determination of the centre of the received signal on the photodetector is aided by algorithms to minimize the amplitude and position uncertainty due to scatter. Although several algorithms are available, "Centre of Mass" calculation shows the best results [16]. As the size and location of the detector are fixed relative to the laser source, the laser displacement system is calibrated for a certain operating range, which is limited by the size and accuracy of the detection sensor. A limiting factor for size detection is the spot diameter of the laser, beyond which a smaller feature than the laser diameter cannot be resolved.

\section{CFRP layup simulation}

This section describes a simulation of the layup and LDS measurements of prepreg CFRP specimens to determine the needed measurement accuracy of the measurement system. During the layup process, each layer of CFRP is stacked according to the design specifications by a tape layer or by hand layup. As every layup process has variance in conditions like the thickness of the sheet, Monte Carlo simulations take this variability into account. These Monte Carlo simulations take the layup process, material aspects (only those directly affecting measurements), additional measurement errors and production flaws into account. To determine the required accuracy of the measurement system for static measurements, several simulated specimens are created in MATLAB, which represent the CFRP specimens. As reference material, unidirectional carbon fibre layers from DeltaTech DT160 that have a typical thickness of $160 \mu \mathrm{m}( \pm 5 \mu \mathrm{m})$ are used. An additional measurement error expected, according to Schmitt et al. [10], is the scattering of the laser beam between carbon fibres. In the simulated specimens, a maximum scattered path of two times the carbon fibre radius is assumed $(0-5 \mu \mathrm{m})$. Figure 2 shows 


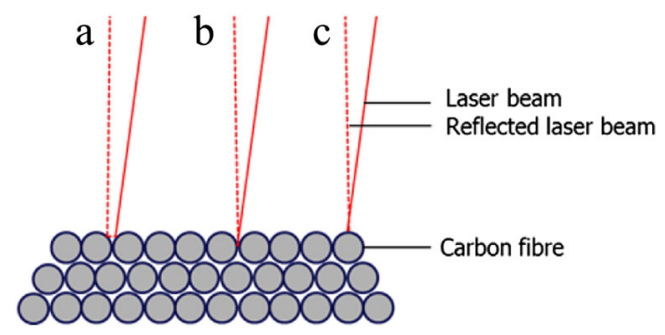

Fig. 2 Schematic overview of potential measurement errors: multiple path reflection returning to the laser head $(a$.), a measurement between two carbon fibres $(b$.) and a reflection from the top of the carbon fibre $(c$.)

the different possible light paths which cause an additional maximum error to the measurement of $5 \mu \mathrm{m}$. Note that the fibres will not be orderly distributed as shown in the schematic graph in a real specimen.

Each layer in the simulated specimen is represented as a matrix (1), and for each layer of CFRP, an error matrix is added to account for the measurement and scatter error. A total random error of between -5 and $+10 \mu \mathrm{m}$ is applied perpendicular ( $X$-axis) to the carbon fibre axis. In the parallel direction ( $Y$-axis) of the carbon fibre, no variations are simulated.

$$
\left(\begin{array}{cccc}
A_{11} & A_{21} & \cdots & A_{n 1} \\
A_{12} & A_{22} & \cdots & A_{n 2} \\
\vdots & \vdots & \ddots & \vdots \\
A_{1 m} & . . & . . & A_{n m}
\end{array}\right)+\left(\begin{array}{cccc}
e_{11} & e_{21} & \cdots & e_{n 1} \\
e_{12} & e_{22} & \cdots & e_{n 2} \\
\vdots & \vdots & \ddots & \vdots \\
e_{1 m} & . . & . . & e_{n m}
\end{array}\right)
$$

A practical size of the specimens is chosen at $50 \times 150 \mathrm{~mm}^{2}$ with a resolution of $20 \mu \mathrm{m}$ in the $X$ - and $Y$-axes. As the height of the simulated specimens is critical to measure flaws, the $Z$ axis has a resolution of $1 \mu \mathrm{m}$. Figure 3 shows a $[0]_{8}$ specimen without any production flaws and an average height in the top layer of $1.28 \mathrm{~mm}$. Each layer overlaps with $1 \mathrm{~cm}$ to show different layers.

Typical production flaws are described in section 1, and these are simulated in the following specimens. Figure 4 shows a specimen including three typical production flaws: a 50 - $\mu \mathrm{m}$-thick foil of $1 \times 1 \mathrm{~cm}^{2}$ is embedded underneath the top layer (a.), the fourth layer is missing (b.) and the first layer has the carbon fibres perpendicular to the $X$-axis (c.).

Figure 5 shows a specimen with two additional typical flaws: in the top layer, wrinkling is simulated (d.) as a
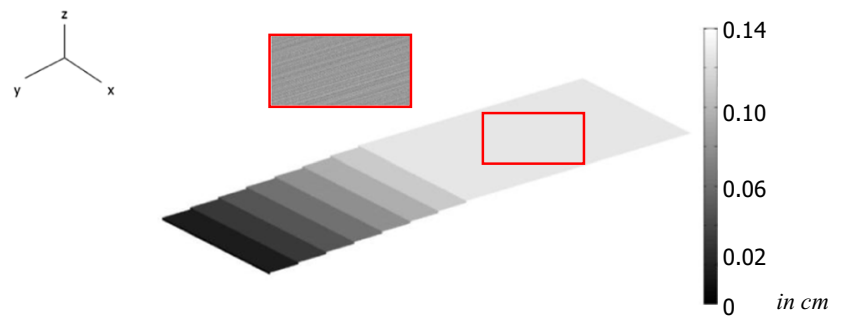

Fig. $3[0]_{8}$ specimen without any production flaws and an average maximum height of approximately $1.28 \mathrm{~mm}$. In the enlarged figure, the orientation of the carbon fibres is clearly visible

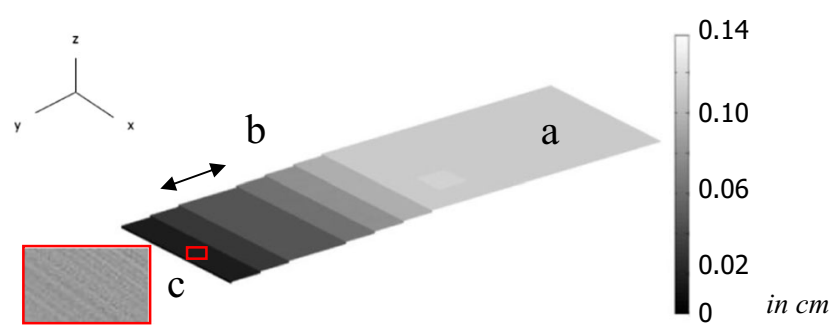

Fig. $4[0]_{7}$ specimen including typical production flaws of an embedded 50 - $\mu \mathrm{m}$-thick foil of $1 \times 1 \mathrm{~cm}(a$.), layer missing (b.) and fibres perpendicular to the $X$-axis (c.)

simplified stepwise accumulation of the CFRP material simulated of $160 \mu \mathrm{m}$ in height. This effect causes a strip of missing material at the edges, which will give an incorrect overlap.

The models only describe the unidirectional samples in static measurements; in the following experiments, crossply CFRP and dynamic measurements will also be evaluated.

\section{Experimental design}

This section describes the experimental set-up used to compare the LDS measurement with the simulations. To demonstrate the use of the technique in the production process, several CFRP specimens were manufactured, measured and analysed. The specimens consist of different types of commonly used materials in CFRP production, unidirectional (160- $\mu \mathrm{m}$-thick) and cross-ply (260- $\mu \mathrm{m}$-thick) CFRP from DeltaTech. The specimens are $150 \mathrm{~mm}$ in length and $50 \mathrm{~mm}$ in width. The following specimens were prepared for laboratory testing to assess the detectability of the production flaws with LDS:

A. Unidirectional $[0]_{8}$ sample without flaws

B. Unidirectional $[0]_{7}$ sample with a missing layer and a piece of enclosed foil of $1 \mathrm{~cm}^{2}$ and $50 \mu \mathrm{m}$ in height

C. Unidirectional $[0]_{8}$ sample with a wrinkle included in the top layer

D. Cross-ply $[0]_{7}$ sample with a missing layer and enclosed foil of $1 \mathrm{~cm}^{2}$

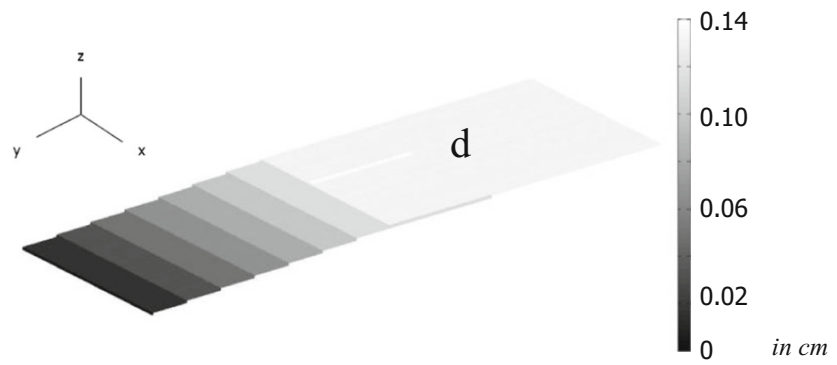

Fig. $5[0]_{8}$ specimen including a typical production flaw of wrinkling (d.) 
Table 2 Specifications of Keyence laser heads [17]

\begin{tabular}{llll}
\hline & & LJ-V7200 & LJ-V7060 \\
\hline Reference distance & & $200 \mathrm{~mm}$ & $60 \mathrm{~mm}$ \\
Measurement range & $Z$-axis & $96 \mathrm{~mm}$ & $16 \mathrm{~mm}$ \\
& $X$-axis & $62 \mathrm{~mm}$ & $15 \mathrm{~mm}$ \\
Repeatability & $Z$-axis & $1 \mu \mathrm{m}$ & $0.4 \mu \mathrm{m}$ \\
& $X$-axis & $20 \mu \mathrm{m}$ & $5 \mu \mathrm{m}$ \\
Light source output (at $405 \mathrm{~nm})$ & $4.8 \mathrm{~mW}$ & $10 \mathrm{~mW}$ \\
Spot shape and size at reference distance & $21 \mathrm{~mm} \times 45 \mu \mathrm{m}$ & $90 \mathrm{~mm} \times 85 \mu \mathrm{m}$ \\
Sampling cycle & $16 \mu \mathrm{s}($ high speed mode) \\
\hline
\end{tabular}

During the laboratory tests, the specimens are measured in absolute height to test the LDS technique on typical CFRP materials and typical production flaws.

The laser heads were chosen based on the results from the simulations and the specifications of the Keyence LJ-V7000 series to detect these typical flaws in production [17]. The specifications of the laser heads are described in Table 2. Either the Keyence LJ-V7200 or LJ-V7060 was used in the set-up as shown in Fig. 6.

To construct a 3D image, a horizontal laser line was used instead of a spot. The laser line was projected on the object via a cylindrical lens and is able to reconstruct a $2 \mathrm{D}$ measurement profile. The sensor head was placed above the test specimen at the reference distance. The specimen was moved manually on a calibrated glider ( $9.5 \mathrm{~mm}$ in height), where the laser measurement is triggered every $100 \mu \mathrm{m}$ on the calibrated glider. The measurements of the laser head were registered via a controller, which is connected to a PC. Not including surface conditions, the LDS is able to measure different profiles and reflectivities simultaneously.

Analysis of the errors introduced during measurements indicated which factors need attention during industrialization of the technique [18]. Besides the scattering $(0-5 \mu \mathrm{m})$ due to the material characteristics and thickness variation $( \pm 5 \mu \mathrm{m})$, which are included in the simulation, other contributing errors are expected in an industrial environment. According to the manufacturer's specifications, the error introduced by the LDS

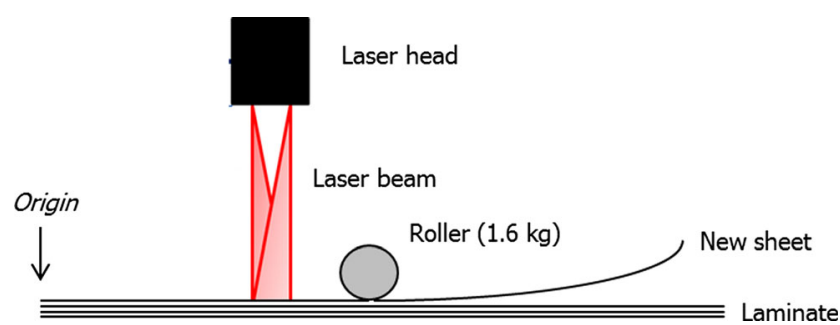

Fig. 7 Experimental set-up for the dynamic measurements

will be the combined error from the sensor and algorithm error. The specified error is $\pm 0.4 \mu \mathrm{m}$ or $\pm 1 \mu \mathrm{m}$ in the $Z$-axis, respectively, for LJ-V7060 and LJ-V7200. Absorption can be another error, but this will only have an influence on the intensity and detectability of the reflected signal and has no influence on the distance measurements. The last source for error will be external influences in an industrial environment, like vibrations. To assess the influence and the allowable limit of vibrations in the measurement system, an experimental setup is used to simulate the dynamic tape laying process. Figure 7 shows the set-up designed to simulate dynamic measurements with the laser displacement sensor. The laser head (LJ-V7060) is fixed above the specimen. While each layer is pressed on the specimen by a $1.6-\mathrm{kg}$ roller, the laminate specimen is moved through the laser beam for consecutive measurements. The measurements start from the origin of the specimen, and each layer is measured and registered in relative height to the last layer. The speed of the system is theoretically $100 \mu \mathrm{m} / 16 \mu \mathrm{s}$ or $6.25 \mathrm{~m} / \mathrm{min}$.

\section{Results}

This section will discuss the results from the static and dynamic measurements.

\subsection{Static measurements}

In specimen $\mathrm{A}$, eight layers of the laminate are measured by LDS and can be separately identified. The results are shown in
Fig. 6 Actual (left) and schematic (right) overview of the experimental set-up using the laser displacement sensor
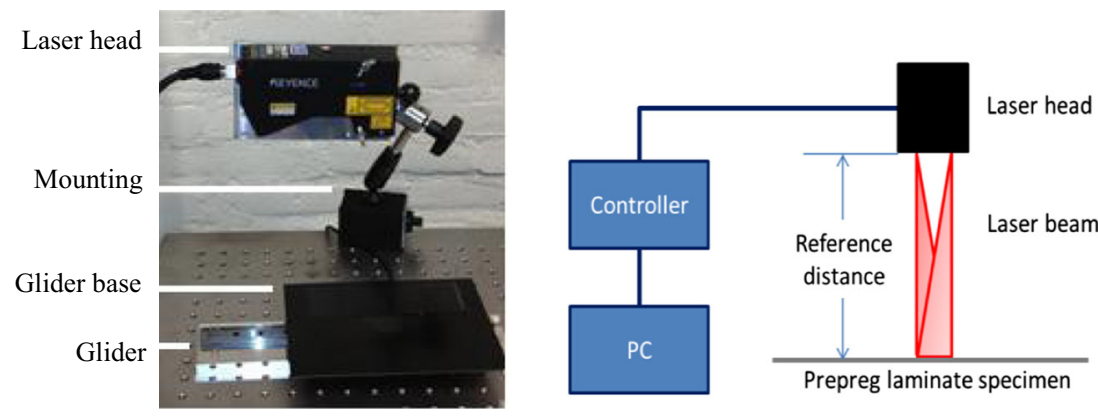
Fig. 8 Measurement of flawless $[0]_{8}$ specimen A (a) and measurements of embedded flaws in specimen B (b) and specimen $\mathrm{C}(\mathbf{c})$

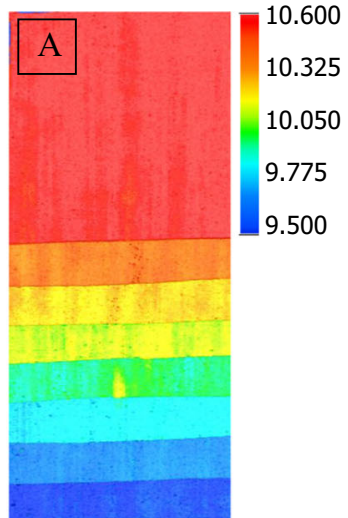

a

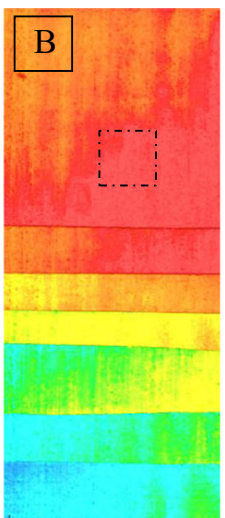

b

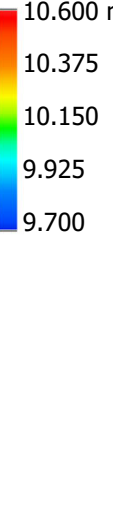

10.375

0.150

9.925

.700

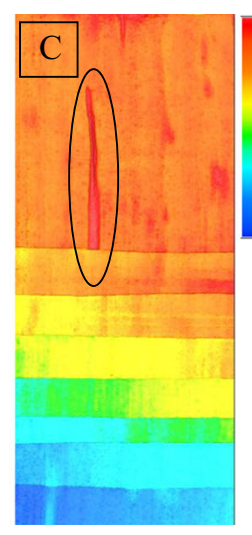

c
Fig. 8a, and a cross section is shown Fig. 9a. The specimen has a maximum height of $1.2 \mathrm{~mm}$ at the top layer and a size of $150 \times 50 \mathrm{~mm}^{2}$. The measured standard deviation is $15 \mu \mathrm{m}$ for LJ-V7200 and $9 \mu \mathrm{m}$ for LJ-V7060 to a $160-\mu \mathrm{m}$ layer, which gives a signal-to-noise (SNR) of 10.7 and 17.8, respectively. The SNR is calculated as the mean over the standard deviation of the measurements. Figure 10 shows the actual surface of a layer of CFRP.

Specimens B and C include flaws and are measured to demonstrate the detectability of embedded flaws. The results are shown in Fig. 8b, c and the cross sections in Fig. 9b, c. In specimen $\mathrm{B}$, the enclosed foil of $1 \mathrm{~cm}^{2}$ of $50 \mu \mathrm{m}$ in height was included beneath the top layer, which is indicated with a dotted box in Fig. 8b. The enclosed foil causes a larger delamination towards the lower right edge of the layer and is clearly detected. The fourth layer is excluded in specimen B and results in a lower total height of the specimen of $1.0 \mathrm{~mm}$ and a clear deviation of the design specification. The incorrect fibre orientation in the first layer cannot be reliably detected, as the fibre radius is below the standard deviation of the measurement system. In specimen $\mathrm{C}$, a wrinkle was introduced in the top layer and causes a maximum height of $1.8 \mathrm{~mm}$ in the top layer.

Table 3 and Fig. 11 show the results of the measurements on specimen D, a bidirectional CFRP laminate of $260-\mu \mathrm{m}$ thick layers. An enclosed piece of foil is included in the top layer, and layer 6 is missing. Table 3 shows the average absolute and relative values of the measurements on specimen $\mathrm{D}$,
Fig. 9 Cross sections $\mathbf{a}, \mathbf{b}$ and $\mathbf{c}$ of measurements with LJ-V7200 of specimens A, B and C ,respectively. The red circles indicate the included foil and the wrinkle

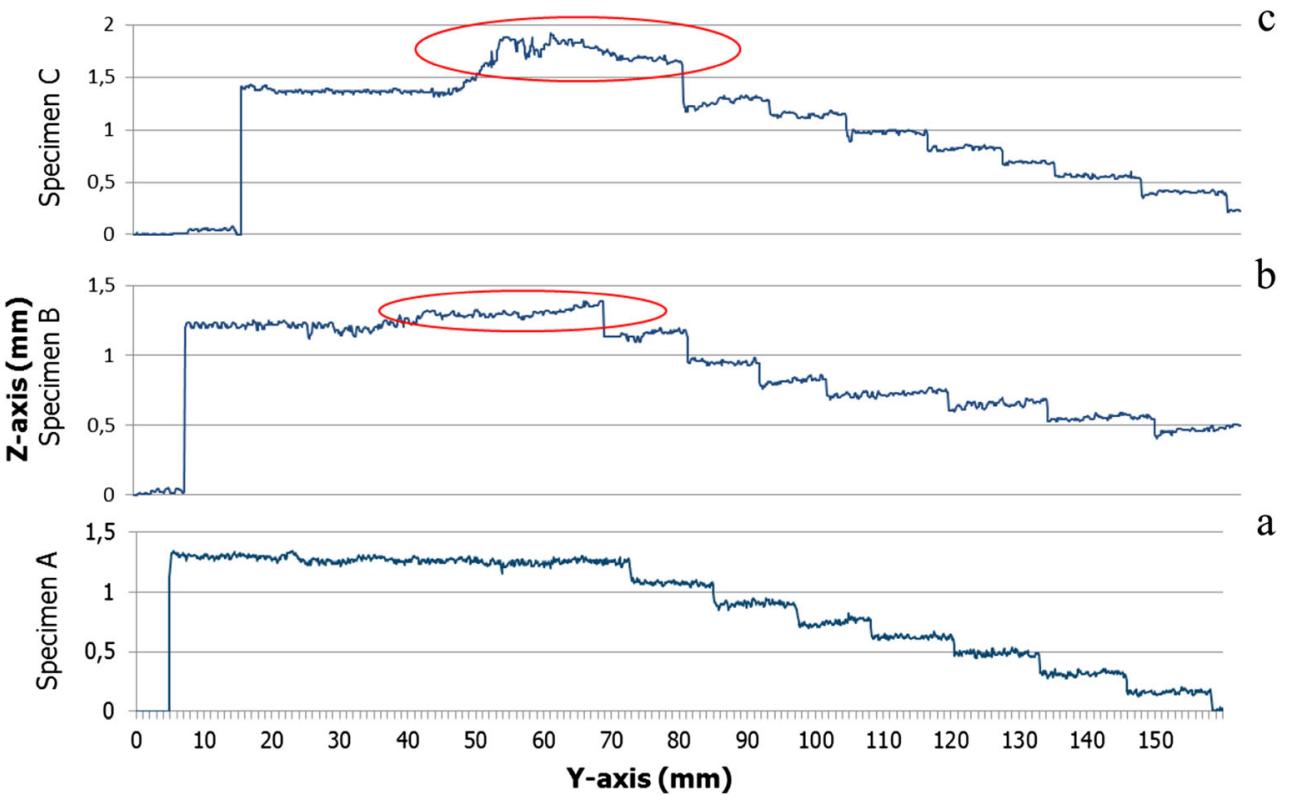




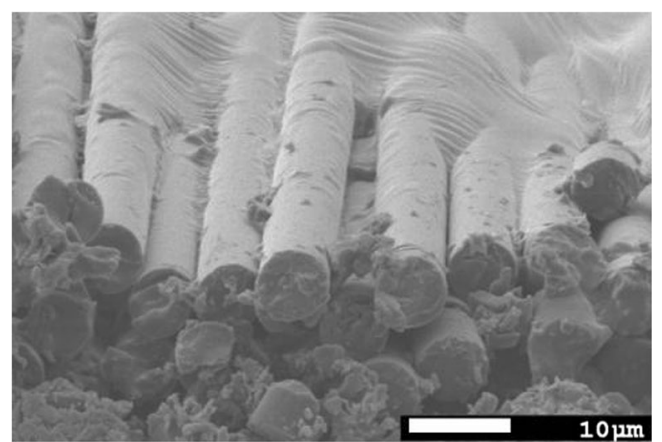

Fig. 10 shows the actual surface of a layer of prepreg CFRP. Measurement was made by the electron microscope at Delft University of Technology

including the flaw. Each layer is clearly distinguished, and the flaw in the top layer is successfully detected. Figure $11 \mathrm{~b}$ shows the results of the LJ-V7200, and Fig. 11a shows the result of the LJ-V7060. The latter shows a higher resolution, but has a limited width of the measurement of $16 \mathrm{~mm}$. In Fig. 11c, the enclosed foil (202- $\mu \mathrm{m}$-thick) is directly visible in the detailed colour map.

\subsection{Dynamic measurements}

The dynamic measurements were performed with the LJV7060, where a tape layup process was simulated, and the results are shown in Figs. 12 and 13 and in Table 4. A 1-cmwide bidirectional CFRP tape was rolled down using a 1.6-kg roller, and each layer was measured to check the quality of the layer in situ before stacking the next layer. The specimen and the laser head start each new layer at the calibrated origin. Each layer was separately measured, and the height of each layer was determined by relating the value of the new layer to the previous measured value. A calibration measurement was made to remove any angle or height dependencies of the specimen or laser head. The embedded foil was successfully detected underneath the fifth layer. The defect is $260 \mu \mathrm{m}$ in

Table 3 Data from measured data from the bidirectional CFRP

\begin{tabular}{lll}
\hline & Absolute height $(\mu \mathrm{m})$ & Calculated relative height $(\mu \mathrm{m})$ \\
\hline Layer 1 & 2501 & 277 \\
Layer 2 & 2778 & 273 \\
Layer 3 & 3101 & 260 \\
Layer 4 & 3361 & 237 \\
Layer 5 & 3598 & 264 \\
Layer 7 & 3862 & 262 \\
Layer 8 & 4124 & 261 \\
Flaw & 4364 & 202 \\
\hline
\end{tabular}

absolute height and is significantly $100 \mu \mathrm{m}$ higher than the surrounding values of layer 5 . The enclosed foil of approximately $1 \mathrm{~cm}^{2}$ can be clearly seen in Fig. 12 and can be clearly distinguished during the dynamic measurements. Figure 13 shows a box plot of each layer, where the data of each layer is represented. The included foil is detected through the identifying significant outliers from the measurement points in layer 5. The outliers are identified as measurement point outside the upper or lower part of the box plot. The total standard deviation varied between 16 and $29 \mu \mathrm{m}$, as vibrations by moving the specimen adds to the measurement errors. The last layer has a higher standard deviation of $75 \mu \mathrm{m}$ due to the included foil, and this is actually another indicator of deviations compared to the previous layers with a lower standard deviation.

\section{Discussion}

This research demonstrates the LDS technique to detect production flaws in situ during layup of composite materials. The Keyence LJ-V7200 and LJ-V7060 sensors are able to detect typical flaws that occur during the production of layup of CFRP. The best accuracy was attained with the LJ-V7060, which resulted in $9 \mu \mathrm{m}$ standard deviation on a layer of $160 \mu \mathrm{m}$ in height. The minimum detectable flaw is $27 \mu \mathrm{m}$ in height and $0.09 \mathrm{~mm}^{2}$ at $3 \mathrm{SNR}$.

Following the measurement of the flawless specimen A, typical production flaws can be successfully detected in other specimens. The embedded piece of foil is indirectly detectable through debonding of the top layer in the lower left corner, and the missing layer in specimen $B$ results in a lower height of the specimen and a geometrical deviation at the missing fourth layer. In specimen C, a wrinkle was introduced in the top layer and caused local height deviations. All flaws thicker than $27 \mu \mathrm{m}$ in height are significantly detectable, and the system is able to detect the following typical flaws in a static set-up:

- Enclosed foil, in this research simulated with 50- $\mu \mathrm{m}$-thick foil

- Missing layer or incorrect overlap, in this research represented as a flaw of $160 \mu \mathrm{m}$

- Wrinkling, in this research simulated with $200-\mu \mathrm{m}$ height

Incorrectly placed layers, and so incorrect fibre orientation, in the layers cannot be clearly detected, where the flaw is smaller than the standard deviation. However, this problem does not exist for tape laying machines, as these use unidirectional CFRP and the orientation of the tape laying direction can be retrieved from the operational steering. Incorrect fibre 
Fig. 11 Results of measurements of specimen $\mathrm{D}$, bidirectional CFRP, with LJ-V7060 (a) and LJV7200 (b) and (c)

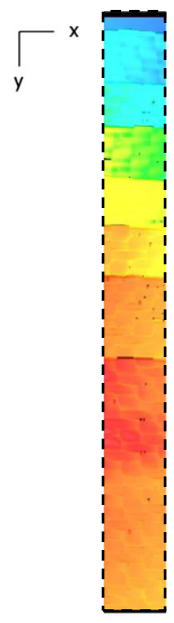

a

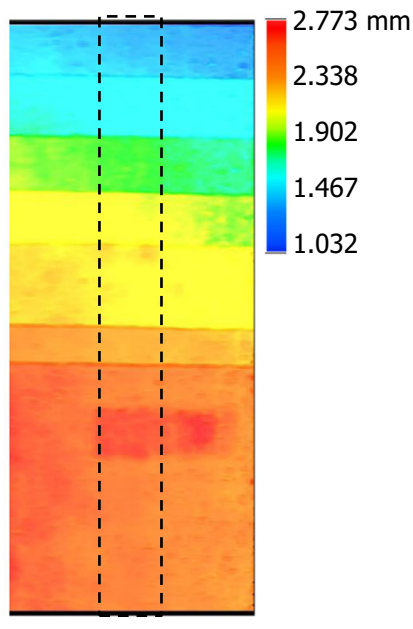

b

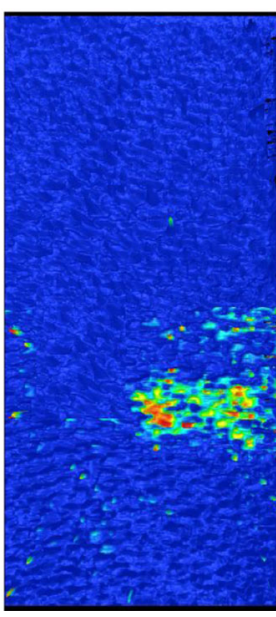

$\mathrm{c}$
$3.450 \mathrm{~mm}$

3.412

3.375

3.337

3.300 orientation shows up at hand layup processes, where layers are manually placed by workers. LDS technique may be able to indirectly detect the orientation by measuring the scattering of the laser light from the height differences of the carbon fibres. Tape laying production use unidirectional CFRP, but hand layup production uses also other types of material like bidirectional CFRP. Table 3 and Fig. 11 show the results of measurements of 200- $\mu$ m-thick bidirectional CFRP, specimen D. Due to the woven structure of bidirectional CFRP, the standard deviation is larger $(\sim 17$ to $53 \mu \mathrm{m})$. However, the foil used for this material is also thicker $(200 \mu \mathrm{m})$. The result is shown in Fig. $11 \mathrm{c}$ by a scaled image showing the $1-\mathrm{cm}^{2}$ embedded foil.

The above discussed measurements are all static measurements of the specimens with several layers of CFRP. In realtime production, the product is dynamically built up layer by layer, where each layer should be measured and analysed compared to the previous layer to monitor the production. In the laboratory measurements, the absolute height of the specimen was measured to detect any geometrical deviations. As a typical tape layer machine lays $30 \mathrm{~m}$ per minute [19] and the laser head operates at $64 \mathrm{kHz}$, measurements can be made every $0.5 \mathrm{~mm}$ to keep up with the machine. This is sufficiently below the allowable defect size of $12.5 \mathrm{~mm}$ in commercial aviation [1]. However, aerospace industries are already investigating smaller defect detection in ranges of 6 to $3 \mathrm{~mm}$.

The foreseen development of the LDS system as a preventative NDE system is provided in Fig. 14 according to Technology Readiness Levels (TRL) [20]. The presented research brings the concept to TRL 4, where all relevant flaws are detected in a laboratory environment. The next step is to validate the economic feasibility to implement LDS in an industrial environment, before demonstrating this in the actual production environment. At TRL 7, prototypes are developed for the hand layup and automated tape laying (ATL) processes, as these have other environmental characteristics. After successful prototyping, LDS can be qualified and installed as a preventative NDE system.

Several disadvantages of the systems need attention during further industrialization. For example, small air bubbles can be detected as geometrical deviations, but will be removed during the curing phase. These air bubbles have a different structure compared to enclosed foil. An air bubble has a spherical geometry compared to a cubic geometry of enclosed foil.
Fig. 12 Results from the simulation of the tape layup process of unidirectional CFRP, first layer on top of the image

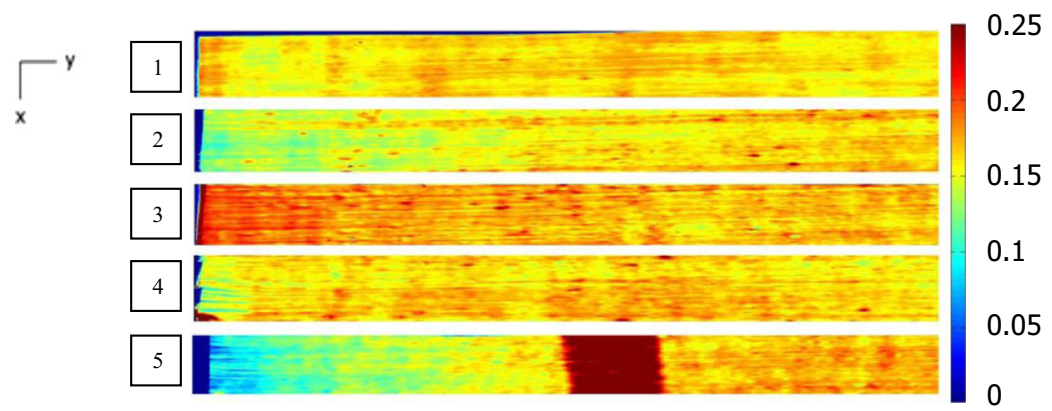


Fig. 13 Box plot diagram of the dynamic measurement data from the unidirectional CFRP. The outliers in layer 5 indicate the embedded foil. (Asterisk indicates interquartile range $(I Q R)=75$ th percentile -25 th percentile.)

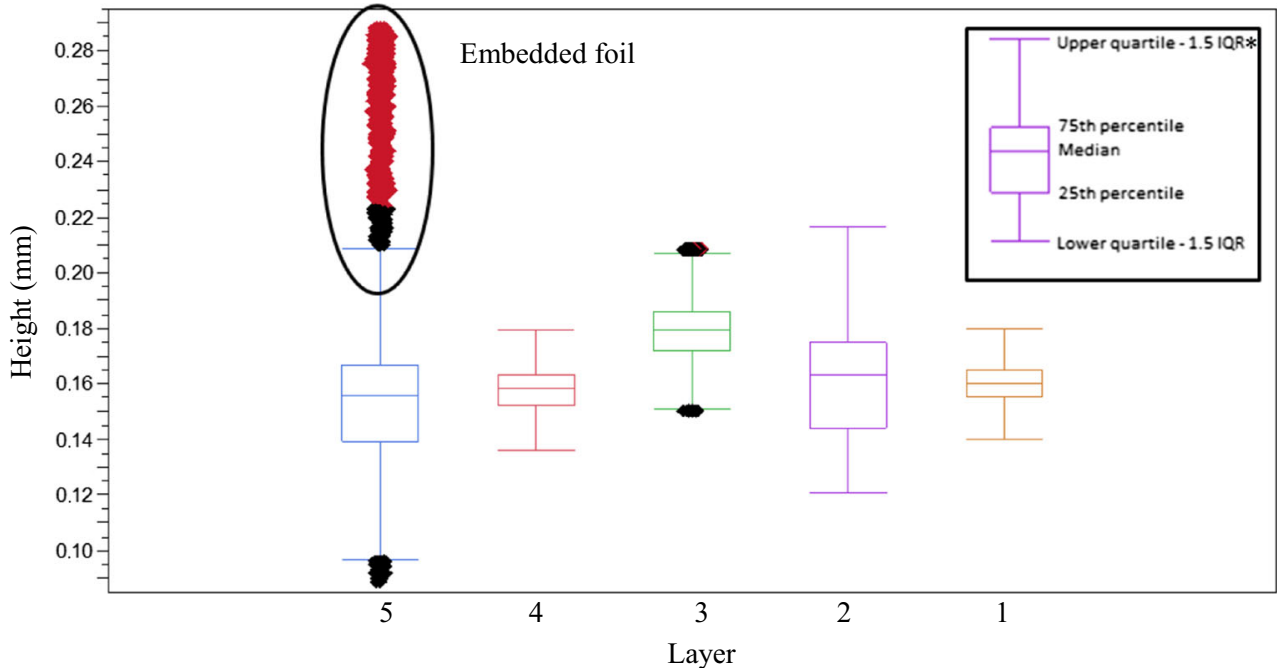

However, these air bubbles must not trigger any monitoring system as a false flaw detection system. Another disadvantage of the system is the limited width of the laser signal, although for a tape layer this is not an issue as CFRP tape are typically smaller in width than the laser signals [21]. For hand layup products, this does not hold up, as in hand layup large layers are stacked. This should imply several laser heads to cover the complete width of the product or a mountable laser head fixed on the layup roller. These solutions will cause higher costs or more vibrations, respectively. Additional illumination with a near UV light source will not impact the specimen through chemical curing or heating of the CFRP. Mascioni et al. [22] has demonstrated the needed illumination times to cure typical epoxy resin in prepreg with UV light, and the added heat by the LDS light source is negligible.

The described flaws are all geometrical deviations from design specifications, so the candidate in situ production monitoring system must be capable of measuring these during operations. By moving the laser source or the measured object, a 3D profile is constructed, but during the industrialization of the in situ measurement system, these geometrical measurements must be coupled to the original CAD design

Table 4 Data of dynamic measurement data from the unidirectional CFRP

\begin{tabular}{lll}
\hline & Relative height $(\mu \mathrm{m})$ & Standard deviation $(\mu \mathrm{m})$ \\
\hline Layer 1 & 164 & 15.9 \\
Layer 2 & 178 & 28.6 \\
Layer 3 & 173 & 28.6 \\
Layer 4 & 163 & 29.0 \\
Layer 5 & 155 & 75.2 \\
\hline
\end{tabular}

specifications and the numerical steering of the tape laying process. The dynamic measurements showed an increased standard deviation of 16 to $29 \mu \mathrm{m}$ due to vibrations in the set-up. In calibration measurements at the manufacturer, a vibration error of $7 \mu \mathrm{m}$ is measured. Any additional vibrations from an industrial environment must be below the allowable standard deviation limit. This limit can be calculated through the $K$-means sampling method [23]. The K-means sampling method and the possible 25 measurement points to detect a flaw of $12.5 \mathrm{~mm}$ or larger, shows a maximum allowable standard deviation of $42 \mu \mathrm{m}$ to distinguish $210 \mu \mathrm{m}$ from $160 \mu \mathrm{m}$ (i.e. the difference between a layer of CFRP and a layer with $50-\mu \mathrm{m}$ foil embedded). To significantly detect a flaw of $50 \mu \mathrm{m}$, amplitude vibration levels lower than $33 \mu \mathrm{m}$ are accepted or need to be above $64 \mathrm{kHz}$ (i.e. interrogation speed) to be filtered out.

The techniques described will be developed further with an industry partner of the Structural Integrity \& Composites Group at Delft University of Technology.

\section{Conclusion}

This research investigated the suitability of the LDS technique as an in situ monitoring system for CFRP materials. The technique is able to detect typical flaws from the production environment, such as enclosed foils, missing layers and wrinkles in the specimen. The technique can be used for unidirectional and bidirectional CFRP materials and is applicable for static measurements of specimens as well for dynamic measurements, comparable to tape laying machines. 
Fig. 14 The technical roadmap of the further development of LDS as a preventative NDE system in the Technology Readiness Levels (TRL)
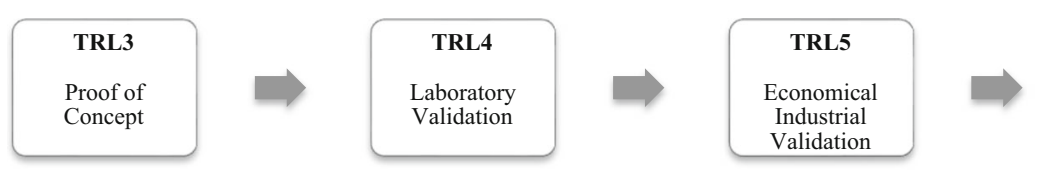

TRL6

Industrial

Demonstration

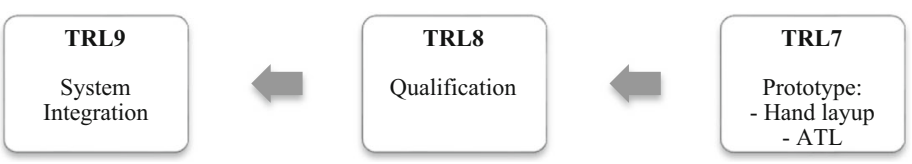

Future research needs to focus on how to integrate the system real-time into the production process and whether the system can operate independently from the workers or tape layers to monitor the quality in situ during layup. After successful in situ detection of production flaws, follow-up research needs to address how to remove the embedded flaw during the production without damaging the product. To determine the requirements for such system, industry partners of the Aerospace NDT laboratory will contribute to this research.

Acknowledgments The authors like to acknowledge Keyence for the loan of laser displacement sensors to demonstrate the proof of principle of the approach.

Open Access This article is distributed under the terms of the Creative Commons Attribution 4.0 International License (http:// creativecommons.org/licenses/by/4.0/), which permits unrestricted use, distribution, and reproduction in any medium, provided you give appropriate credit to the original author(s) and the source, provide a link to the Creative Commons license, and indicate if changes were made.

\section{References}

1. Baker AA, Dutton S, Kelly D, Kelly DW (2004) Composite materials for aircraft structures. American Institute of Aeronautics and Astronautics

2. Campbell FC (2004) Manufacturing processes for advanced composites. Elsevier

3. Peiponen KE, Myllylä R, Priezzhev AV (2010) Optical measurement techniques: Innovations for industry and the life sciences. Springer

4. Amann MC, Bosch T, Lescure M, Myllylä R, Rioux M (2001) Laser ranging: a critical review of usual techniques for distance measurement. Opt Eng 40(1):10-19

5. Carvalho FD, Davies R, Dinis J, Malta CA, Guedes AS, Silva JF (1994) Laser triangulation technique for textured surface shape analysis in industrial applications. Society of Photo-Optical Instrumentation Engineers, Boston, pp 170-180

6. Fu G, Menciassi A, Dario P (2012) Development of a low-cost active $3 \mathrm{D}$ triangulation laser scanner for indoor navigation of miniature mobile robots. Robot Auton Syst 60(10):1317-1326

7. Zhang L, Xie Y (2009) Development of automatic visual inspection sensor in robotic tailored blank welding. Wuhan

8. Ouyang Q, Zhang LZ, Zhao LM, Zhang XL, Chen DF (2011) Experimental study on quantitative surface defect depth detection based on laser scanning technology in continuous casting. Ironmak Steelmak 38(5):363-368

9. Shetty D, Campana C (2012) Precision measurement method of misalignment, cracks, contours and gaps in aerospace industry. San Antonio, TX

10. Schmitt R, Orth A, Niggemann C (2007) A method for edge detection of textile preforms using a light-section sensor for the automated manufacturing of fibre-reinforced plastics. in SPIE Optical Measurement Systems for Industrial Inspection V. p. 661609 Munich

11. Schmitt R, Niggemann C, Mersmann C (2008) Contour scanning of textile preforms using a light-section sensor for the automated manufacturing of fibre-reinforced plastics. In SPIE Photonics Europe . p. 70031I-1 Strasbourg

12. Schmitt R, Niggemann C, Mersmann C (2009) Laser light-section sensor automating the production of textile-reinforced composites. in SPIE Optical sensors. p. 73560P-1 Prague

13. Schmitt R, Mersmann C, Damm B (2010) In-process 3D laser measurement to control the fiber tape-laying for composite production. In SPIE Photonics Europe. p. 661609-3 Brussels: SPIE

14. Faidi W (2012) Wind turbine manufacturing process monitoring. General Electric Global Research Center, Niskayuna

15. Kennedy WP (1998) Basics of triangulation sensors. Sensors (Peterborough, NH) 15(5):80-83, p. 76, 78

16. Koch T, Breier M, Li W (2013) Heightmap generation for printed circuit boards $(\mathrm{PCB})$ using laser triangulation for pre-processing optimization in industrial recycling applications. In 2013 11th IEEE International Conference on Industrial Informatics, INDIN 2013. p. 48-53 Bochum

17. KEYENCE (2012) LJ-V7000 series Keyence: Osaka, Japan

18. Bukshtab M (2012) Applied photometry, radiometry, and measurements of optical losses. p. 1-725

19. Goel A (2000) Economics of Composite Material Manufacturing Equipment, in Dep. Mechanical Engineering. Massachusetts Institute of Technology

20. Commission E., G (2014) Technology readiness levels (TRL), HORIZON 2020 - WORK PROGRAMME 2014-2015 General Annexes, Extract from Part 19 - Commission Decision C 4995. 2014.

21. Dextra. www.dextragroup.com/construction-products/cfrp-tape. 2013 [August 2013]

22. Mascioni M, Ghosh NN, Sands JM, Palmese GR (2013) Electron beam and UV cationic polymerization of glycidyl ethers PART II: reaction of diglycidyl ether of bisphenol A. J Appl Polym Sci 130(1):487-495

23. Scott A, Knott M (1974) A cluster analysis method for grouping means in the analysis of variance. Biometrics p. 507-512 